\title{
A study on the existence of ground subsidence under road pavement using ground penetrating radar
}

\author{
N. M.Zahari *, N. H. M Abu Bakar, M. H. Zawawi \\ Department of Civil Engineering, Universiti Tenaga Nasional (UNITEN), Kajang, Malaysia
}

\section{A RT ICLE INFO}

\section{Article history}

Received 28 February 2017

Received in revised form

20 September 2017

Accepted 5 October 2017

\section{Keywords:}

Ground penetrating radar

Ground subsidence

Pavement thickness

Sepang

Petaling jaya

\begin{abstract}
A B S T R A C T
Subsurface information such as ground subsidence formation, thickness and the composition of the subsurface soil is very useful to analysis the current or future-forecasting condition of a ground. The information can be varies to several method includes destructive or non-destructive techniques. However, this study is focus on non-destructive test called Ground Penetrating Radar. This study is about observing existence of cavities, the pavement thickness and the overall condition above the occurred ground subsidence formation. These elements of information are needed as inputs for mitigation/maintenance plan prior sinkhole occurrences. Thicknessinputs for falling weight deflectometer for strength analysis and also composition- behaviour of layer affected nearby affected location.
\end{abstract}

(C) 2017 The Authors. Published by IASE. This is an open access article under the CC BY-NC-ND license (http://creativecommons.org/licenses/by-nc-nd/4.0/).

\section{Introduction}

On the 2nd of July 2014, the major thoroughfare serving the city's bustling Golden Triangle that is Bukit Bintang in Kuala Lumpur was cut off by a $10 \mathrm{~m}$ deep of sinkhole after a burst water pipe caused a section of it to collapse. This incident cannot be overlook by the fact that there's no casualties were reported, but imagine what could have happens if it involve human lives. Not to mention, this also brought lot of echoed responsibilities of not only the local authorities but also the organization that is responsible in constructing the pavements in the first place.

In order to prevent a legit occurrence of sinkholes from happening again, a method of surveying or identifying the existence of sinkholes if there were any should be done prior any construction whether it'll be a building or a pavement. There have many geophysical methods to investigate sinkholes such as resistivity imaging and seismic refraction techniques but the most common method used in pavement study is ground penetrating radar. Besides investigation sinkholes geophysical methods were widely used for environmental hydrology study and subsurface study (Zawawi and Abustan, 2011) Having said that, this so-called unexpected occurrence of sinkholes can become a reality despite

\footnotetext{
* Corresponding Author.

Email Address: mubinzahari@gmail.com (N. M. Zahari) https://doi.org/10.21833/ijaas.2017.012.009

2313-626X/C 2017 The Authors. Published by IASE.

This is an open access article under the CC BY-NC-ND license

(http://creativecommons.org/licenses/by-nc-nd/4.0/)
}

a prior investigation done before any construction took place, this is because the karst is a unique landscape formed by the underground erosion of rocks such as limestone and marble that dissolve in water. Also it is a displacement of surface material cause by natural phenomena or manmade phenomena overtime.

A detail study will be done on a pavement on how to locate and the positioning of sinkholes or potential formations could have taken place under the pavement layer. This study located at expressway in Sepang (SITE A) and Petaling jaya (SITE B). For both expressway ( SITE A and SITE B), it is a three-lane dual carriageway that was built to disperse traffic from congested inner city roads and narrow residential roads leading into Kuala Lumpur city centre from the western suburbs of Petaling Jaya and Damansara and its surrounding areas.

Looking through (Table 1),these are the data obtained by (Bakhshipour et al., 2013) as a detail mapping studies were done on Batu Cave as the study area, it clearly gives out on information of the majority of the fomartion were karstification of karst with various type of colors and porosity values. Allow me to quote, "It has been estimated that nearly $40 \%$ of Kuala Lumpur $(236.827 \mathrm{~km} 2)$ is dominated by limestone"(Bakhshipour et al., 2013).

Having said that, this matter were also concluded by (Abu-Shariah, 2009) that the limestone of this area is part of the Kuala Lumpur as limestone formation. According to (Bakhshipour et al., 2013) on the other hand, the limestone underwent a dolomitisation process through chemical substitution, metamorphism, and re-crystallization 
by thermal solutions of silica (SiO2) leading to the formation of coarse and fine crystal marble.

The technique will produced data of surveys that varies in the dielectric values, which is an indications of how well the water molecules are arranged around and between the aggregate mineral surfaces and how much free water or "loosely bound water" exists in materials, is a much better indicator of the strength and deformation properties of road aggregates than the moisture content. Each aggregate type has a unique relationship between material dielectric and moisture content. If we gained a profile the amplitude of the GPR reflection from the top of the granular layer is used to calculate the dielectric of that layer. Furthermore, if obtained high dielectric values $<16$ that calculated from a GPR data, for example, this can be concluded as a good indicators for potential problems in the layer (Scullion and Saarenketo, 1998).

To clarify the main hazard sources in shallow karst formation location. The existence of subsidence related such as cavities below the GPR penetration depth or dissolution processes can also represent an important warnings or hazard source. The presence of existence of subsidence processes without development of fully-grown cavities can be inferred by the characterization of the soil structure by the doing survey with Ground Penetrating Radar (GPR). Indirectly a brief soil profile can also be produce from this assessment. According to (Mellett, 1995), a Ground Penetrating Radar (GPR) can display numbers of benefits compare to other geophysical methods, particularly in urban settings, since structural steel and vibrations from roadway or air traffic make it difficult to use magnetic, or seismic methods with an acceptable reliability.

\section{Methodology}

In this study, along with Ground Penetrating Radar (GPR) as the techniques for investigation. A significant figures of dielectric values from this assessment using Ground Penetrating Radar (GPR) will provide a brief analysis of the sinkholes position and it characteristics shall be obtained from the chosen site. In terms of the composition of the pavement layer can be identify before and after the formations of karstic cavity. The results obtained in this work can be useful to define the survey strategy for similar studies in karst environments formation or pavement information on thickness for example.

These significant figures can be taken as the comparison elements in terms of dielectric values. In returns, there will be a result differences between air-filled voids or water-filled voids. These conditions will gives out a fluctuation in readings appeared on the receiver antenna. Through all these, it should reach the objectives stated above.

Fig. 1 is a simple flowchart can be illustrate how the flow of sending and receiving wave that been done by the equipment and how it will be sending to the display scrren to gives out the results. For this thesis, equipment named GSSI Roadscan 30 were used and chosen as the geophysical equipment to make the surveying on the fieldwork. It can goes up to $9 \mathrm{~m}$ underground to detect any ground subsidence under the pavements.

All the raw signals gathered onside will be process using software named RADAN7. The raw data is an input and will be process by RADAN7 for further analysis. By using RADAN7, there is a feature called layer interpretation which resulted the 2Dradagram,this 2D-radargram can fulfill the first objective is to locate ground subsidence, once the feature applied, the data frame will be analyse to find any irregularities manually by using our observation on the signal appeared in the 2D-radargram.

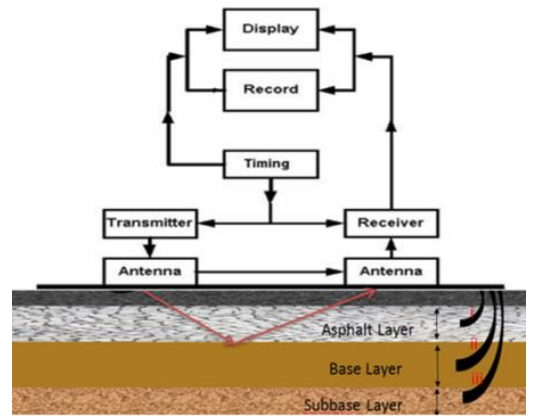

Fig. 1: Flowchart on the cycle of ground penetrating radar process

\section{Result and discussion}

For the data analysis, in order to remove background interference, migrate hyperbolas, calculate accurate depth, and etc. All data collected in the form of radar waveform will undergo processing process and analysis using GSSI GPR processing software known as Radan7. The target survey shall be mark and presented in line scan format. The analysis using mentioned software involves application of mathematical functions to the data. In this section, conducted is the project using GPR - Air Coupled Antenna 1.0Ghz to evaluate and determine possible problem on Site A in Sepang and Site B in Petaling Jaya as chosen locations, presence of anomalies, and depression level that occurred 2 to 3 meters away from a Connecting Drain and 3 to 5 meters away from a utilities pipe.

The data were collected on $10 \mathrm{~km}$ in length for both site A and site B with 100 meters interval for raw data frame collection. Cavities can be air filled or water filled depends on condition of the pavement. There are two areas chosen respectively for both Site A and Site B. As we can refer in Fig. 2, on the left is the cavities located on Site A in Sepang and on the right is from Site B in Petaling Jaya. The depth of range was collected at 5 meters as the waveforms are more interpretable compared to depth range of 8 or 9 meters.

As for Site A which situated in Sepang, the cavities were found approximately on the sixth kilometers $(6.010 \mathrm{~km})$ and from the radargram generated by RADAN7, it is approximately 4 meter wide with a $3.5 \mathrm{~m}$ deep. However the trend of the cavities 
formation is shown as continuous parabolic curve which also mean that the cavities is propagating further up more than the sixth kilometer as look carefully in Fig. 2 The area of the cavities is located nearer to the outmost layer that is asphalt layer in this pavement case; the parabolic curve is starting its peak at the depth of $0.8 \mathrm{~m}$ from the asphalt surface. There are negative peak and also positive peak of parabolic curves visible in the radargram of the Site A.
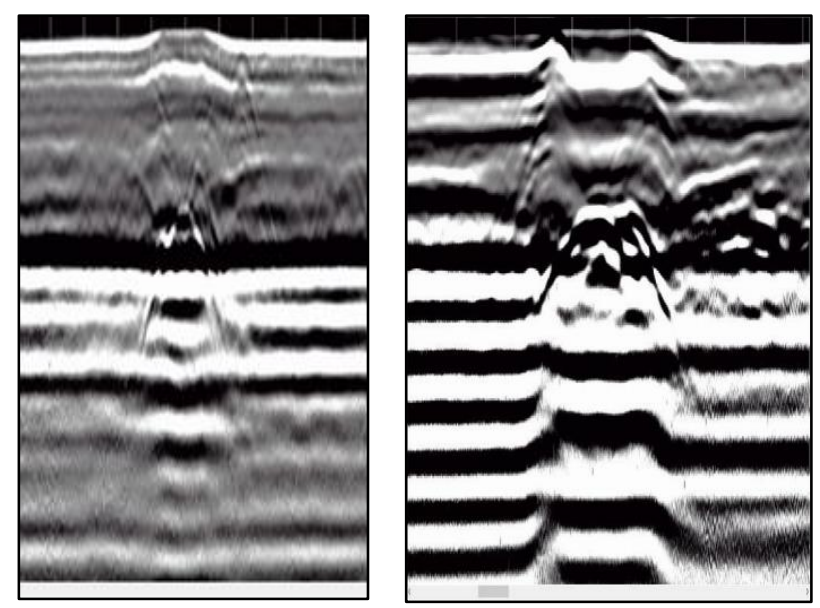

Fig. 2: The cavities found on Site A (left) and Site B (right)

Several positive peaks also were found beneath the asphalt layer in Fig. 3 where the cavities formed, this is interpreted as there might be a possibility of weather factor or the hydrostatic pressure rose up to almost expelled from the asphalt layer.

On the right side of Fig. 2 is the radargram from Site B in Petaling Jaya. Along the $10 \mathrm{~km}$ length of the site, there is one area found with cavities formation, the cavities were found approximately on the fourth kilometer $4.037 \mathrm{~km}$ ) which shown in the radargram generated by the RADAN7, as can refer in Fig. 4, it is approximately $3.8 \mathrm{~m}$ wide and $3.0 \mathrm{~m}$ deep.

As for Site B, the trend of parabolic curve also seems to be propagating further up more the fourth kilometer. However the layer affected is more severely damaged compare to the one in Site A. This matter will be discussed in the next section 4.2 about evaluating the pavement layer which surrounds the cavities area. Both negative and the positive peak can be seen in the Site B.

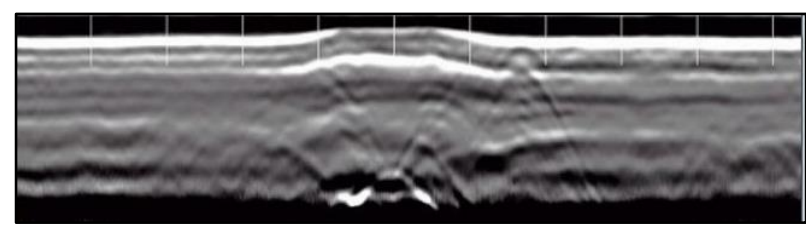

Fig. 3: The continuous of parabolic curves formed in 2Dradargram image

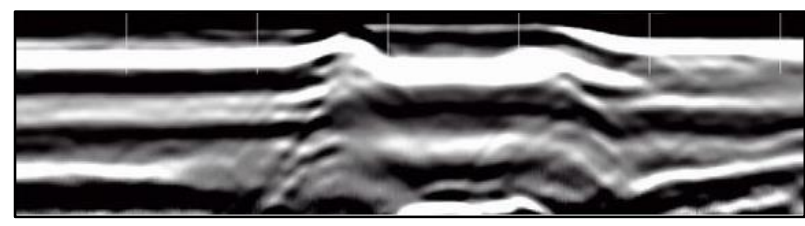

Fig. 4: The parabolic curve in radargram for Site B

In this section, the composition of pavement layer nearby the occurred cavities will be evaluate, the formation of cavities will never leave pavement in sound condition. It will affect nearby area and it will also jeopardize the safety of the nearby area. After the cavities occurred, it will have the tendencies to spread to other place either by seeping through voids or simply causes pressure build up which lead to problem such as depression and changing in shape makes it uneven (Fig. 5).

By referring Fig. 6, for the Site A there is several trend of unevenness found above and nearby the cavities, the above part is also found with positive peak parabolic curve and this acknowledged the existence of water, this is due also to the hydrostatic pressure from the beneath cavities that contain also water, hence the hydrostatic pressure rose up and eventually pressuring the top layer to form some sort of heaving condition.

As for the area which having depression in the red circle in Fig. 6, the depression is found between the water and air-filled, the probability water is spreading through the opening wall of the cavities and seep into the area is high, it started to seep through the layer to the side of the cavities.
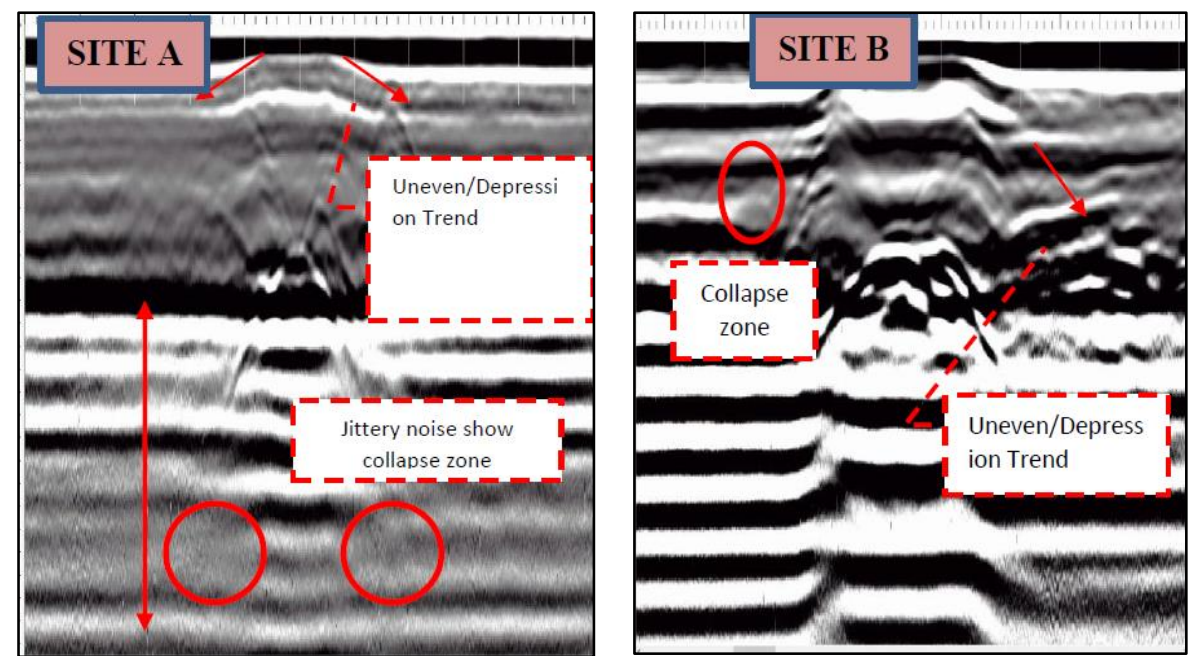

Fig. 5: The composition of pavement layer consists various defects formation 


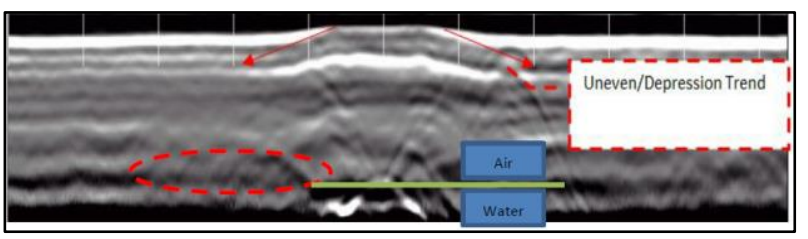

Fig. 6: Unevenness trend occurred nearby the cavities in Site A

Other than the unevenness trend found on Site A, there are also collapse zones occurred nearby the cavities, these collapse zones were formed due to water seepage that penetrates from the cavities to the nearest layer and resulting erosion were happening over time hence the blurring effects appeared in the radargram of Site A as shown in Fig. 7. Note that a well design pavement layer should be showing a constant straight line to portray the layer were not changing whether in shape or it is perfectly in a condition same as the design should be.

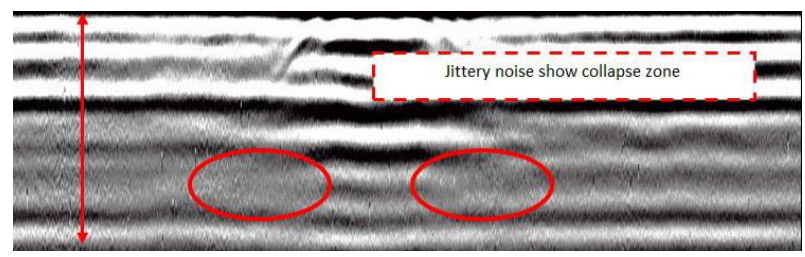

Fig. 7: The blurring effects appeared as collapse zone in Site A

The pavement thickness can be directly determined as soon as the raw data of the radar signals is having layer interpretation features applied to it, the depth can be gained by doing picking layer in RADAN7 software. The thickness of every; and each layer can be obtained. Referring to Fig. 8 is the depth pick for Site A and the Fig. 9 is the depth picked for Site B. The depth were picked by points, it could be single points or can be picked by block. Note that the depth of the layer is can easily exported to excel format for documentation purpose, the depth can be an enormous data in excel, however for this study will provide the depth in the appendix section. The depth that has been pick will be in excels form once it's exported as shown in Table 1.

Fig. 9 shows layer interpretation of different soil materials in Site B that are detected from the processed data based on visible and continuous waveforms. These depth(s) might vary depending on the soil properties and moisture content of the subsurface. However, data interpretation and layers picking using Radan7 software could not be performed beyond the depth of 2.2 meters. This might be due to noise and high moisture content that has absorbed all the signals.

\section{Conclusion}

Total there is three objectives in this study is to determine the position of cavities in the pavements layer, investigate the composition of pavements layer above the occurred cavity and lastly to evaluate the pavement thickness by using Ground Penetrating Radar technique.

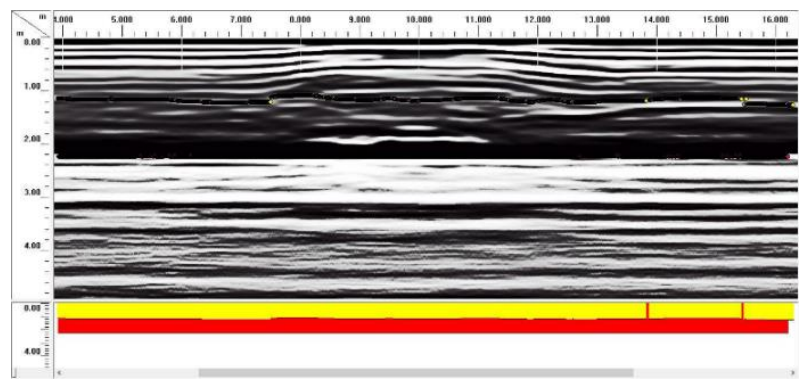

Fig. 8: The depths picking for Site A

Table 1: The depth that has been picked by RADAN7 software in Excel format

\begin{tabular}{ccccc}
\hline Dist.(m) & Name & Depth(m) & Name & Depth(m) \\
\hline 6.000 & Layer 1 & 1.170 & Layer 2 & 2.218 \\
6.500 & Layer 1 & 1.194 & Layer 2 & 2.220 \\
7.000 & Layer 1 & 1.199 & Layer 2 & 2.220 \\
7.500 & Layer 1 & 1.141 & Layer 2 & 2.220 \\
8.000 & Layer 1 & 1.077 & Layer 2 & 2.220 \\
8.500 & Layer 1 & 1.120 & Layer 2 & 2.220 \\
9.000 & Layer 1 & 1.155 & Layer 2 & 2.220 \\
9.500 & Layer 1 & 1.142 & Layer 2 & 2.220 \\
10.000 & Layer 1 & 1.162 & Layer 2 & 2.220 \\
10.500 & Layer 1 & 1.147 & Layer 2 & 2.220 \\
11.000 & Layer 1 & 1.127 & Layer 2 & 2.220 \\
11.500 & Layer 1 & 1.154 & Layer 2 & 2.220 \\
12.000 & Layer 1 & 1.171 & Layer 2 & 2.220 \\
12.500 & Layer 1 & 1.177 & Layer 2 & 2.220 \\
13.000 & Layer 1 & 1.182 & Layer 2 & 2.210 \\
13.500 & Layer 1 & 1.170 & Layer 2 & 2.217 \\
14.000 & Layer 1 & 1.143 & Layer 2 & 2.218 \\
\hline
\end{tabular}

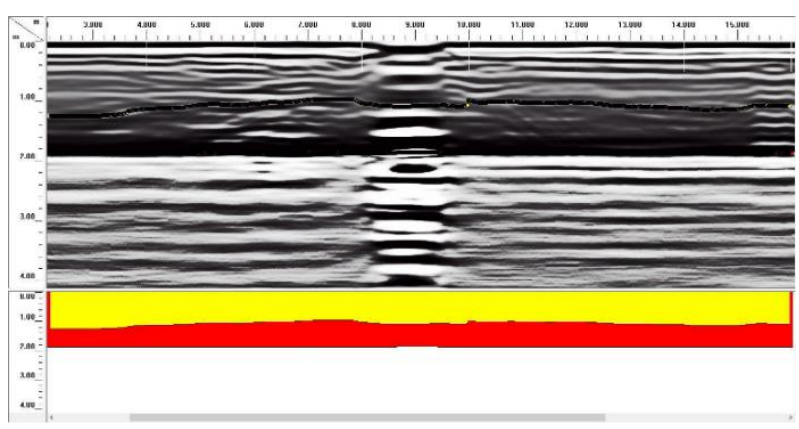

Fig. 9: The depths picking for Site B

Through this study, 2 potential sinkholes found each on both Site A and Site B. It is located approximately $6.010 \mathrm{~km}$ for Site A and $4.038 \mathrm{~km}$ out of $10 \mathrm{~km}$ length of site area. The next objective is to investigate the composition of pavement layer nearby the cavities. There is unevenness and collapse zone found nearby ground subsidence and this can be referring in result section. Lastly is to find depths, the depths is successfully picked and exported in excel format. In terms of recommendation, as for the location, it would be more comprehensive in terms of analyzing results if the site is from different function such as house residential area or natural soil such as a park. These result might be varies in 2D-radargram formation because of the different layer depths. The 2Dradargram frame would appear differently also in number of layer since the function is also different, 
hence it would be clearer in doing comparison for different types of site functions.

\section{References}

Abu-Shariah MI (2009). Determination of cave geometry by using a geoelectrical resistivity inverse model. Engineering Geology, 105(3): 239-244.

Bakhshipour Z, Haut BB, Ibrahim S, Asadi A, and Kura NU (2013). Application of geophysical techniques for $3 \mathrm{~d}$ geohazard mapping to delineate cavities and potential sinkholes in the northern part of Kuala Lumpur, Malaysia. The Scientific World Journal, 2013: Article ID 629476, 11 pages. https://doi.org/10.1155/2013/629476
Mellett JS (1995). Ground penetrating radar applications in engineering, environmental management, and geology. Journal of Applied Geophysics, 33(1-3): 157-166.

Scullion $\mathrm{T}$ and Saarenketo $\mathrm{T}$ (1998). Applications of ground penetrating radar technology for network and project level pavement management survey systems. In the $4^{\text {th }}$ International Conference on Managing pavements, Durban, South Africa.

Zawawi MH and Abustan I (2011). Detection of groundwater aquifer using resistivity imaging profiling at Beriah landfill site, Perak, Malaysia. Advanced Material Research, 250-253: 1852-1855. https://doi.org/10.4028/www.scientific.net/ AMR.250-253.1852 